\title{
INACTIVE HEPATITIS B CARRIER AND PREGNANCY OUTCOMES
}

\author{
Rabiah Anwar, Kashif Razzaq \\ Pakistan Naval Ship, Shifa Hospital, Karachi Pakistan
}

\begin{abstract}
Objective: To assess the impact of hepatitis B carrier status on pregnancy and perinatal outcome. Study Design: Cross sectional study.

Place and Duration of Study: Department of Gynaecology and Obstetrics, Pakistan Naval Ship Shifa Hospital, Karachi, from Feb 2017 to Jan 2018.

Methodology: A total of 9526 women delivered during study period. 9305 women fulfilling the inclusion criteria were included in study. Two hundred and twenty one (221) women were excluded because of not fulfilling the inclusion criteria. Out of study group, 9104 women were HBsAg negative while 201 had positive hepatitis B carrier status. Antenatal complications (such as gestational diabetes, gestational hypertension, pre eclampsia), mode of delivery (vaginal delivery, elective cesarean, emergency cesarean) and perinatal outcomes (preterm delivery, low birth weight at delivery, live birth rate, APGAR score at 1 and $5 \mathrm{~min}$ ) were observed among hepatitis B carrier and noncarrier.

Results: There was no significant difference in point prevalence of major antenatal complications, mode of delivery and perinatal outcomes in HBsAg carriers and noncarriers. A slightly higher rate of preterm birth was observed in hepatitis B carriers (4.9\%) as compared to noncarriers $(2.6 \%)$.

Conclusion: Hepatitis B carriers have slightly increased risk of preterm delivery.
\end{abstract}

Keywords: Hepatitis B carrier status, Pregnancy outcome, Perinatal outcome.

This is an Open Access article distributed under the terms of the Creative Commons Attribution License (http://creativecommons.org/licenses/by/4.0), which
permits unrestricted use, distribution, and reproduction in any medium, provided the original work is properly cited.

\section{INTRODUCTION}

Hepatitis B infection is a global health problem imposing a heavy burden on health system ${ }^{1}$. According to estimation of World Health Organization (WHO), 257 million people were living with chronic hepatitis B infection (defined as hepatitis B surface antigen positive) in $2015^{2}$. This infection is caused by double stranded DNA virus belonging to hepadna viridae family and may cause serious complications like acute and chronic hepatitis, cirrhosis liver and hepatocellular carcinoma ${ }^{3}$. The inactive hepatitis B virus is 100 times more contagious and more robust than $\mathrm{HIV}$, and it often goes undetected ${ }^{4}$. This virus is transmitted through blood, blood products and sexual contacts. There is infrequent transplacental transmission of infection to the fetus. Vertical transmission of infection is mainly in peripartum period with infected vaginal secretions and breast milk ${ }^{5}$. That is why virus transmission and fetal

Correspondence: Dr Rabiah Anwar, Classified Gynaceologist, PNS Shifa Hospital, Karachi Pakistan

Received: 29 Oct 2019; revised received: 27 Jun 2020; accepted: 28 Jul 2020 health are important concerns worldwide.

For HBV screening, Hepatitis B surface antigen (HBsAg) testing is recommended in all pregnant women. HBV infection during pregnancy has peculiar aspects among which are effects of pregnancy on this infection and effects of this infection on pregnancy and its outcome. It is believed that infected pregnant ladies are usually asymptomatic and diagnosed during routine antenatal screening. Pregnant ladies with acute or chronic HBV infection have similar course of disease as general adult population. Simple Hepatitis B virus infection does not increase maternal mortality and it is generally believed that this viral infection has no serious effect on pregnancy ${ }^{7}$. It does not cause teratogenic effect on fetus. This virus does not cross the placental barrier but the inflammation which virus elicits, may affect the pregnant lady negatively. This may result in negative pregnancy outcomes ${ }^{8}$ as some studies have explored impact of this infection in pregnancy outcomes such as preeclampsia, preterm birth, gestational diabetes mellitus 
and pre labor rupture of membrane and low birth weight.

It is important both for health care providers and patients to be aware of effects of hepatitis B on pregnancy and its outcomes. Since many studies results are controversial, we have done this study to partly clarify the effect of HBV carrier status on pregnancy and perinatal outcome.

\section{METHODOLOGY}

This cross sectional study was conducted in department of Gynae/Obs, PNS Shifa Karachi for the period of 12 months, from February 2017 to January 2018. PNS Shifa Karachi is a referral institute and a tertiary care hospital catering for large number of army and civilian personnel. Sample size was calculated using WHO sample size calculator. Assuming 5.2\% prevalence of hepatitis B in pregnant women', a minimum sample size of 76 was calculated to provide study $80 \%$ power in assessing impact of Hepatitis B carrier status on pregnancy and perinatal outcome.

A total number of 9526 women were delivered during the study period. In this 9305 women fulfilled the inclusion criteria and included in study. Two hundred and twenty one women were excluded because of nonfulfilling inclusion criteria. Of study group, 9104 women were HBsAg negative and 201 had positive hepatitis B carrier status. Since PNS Shifa hospital has universal antenatal screening for Hepatitis B surface antigen (HBsAg) carrier status, all women in sample were checked for hepatitis B status at the time of their booking visit. For unbooked patients, hepatitis B status was checked during hospital admission. Blood samples were sent to PNS Shifa laboratory and tested for HBsAg status by enzyme linked immunoassay. In this cohort study, participants were divided in to two groups, those having negative HBsAg status were included in group A and those having positive carrier status were included in group B.

The ladies included were between 20 and 35 years of age, had gestational age of 28-42 weeks, singleton pregnancy and no medical disorder such as hypertension and diabetes mellitus prior to pregnancy. The ladies having multiple pregnancy, pre-pregnancy medical illness (such as $\mathrm{DM}$, hypertension) and known infection with hepatitis A, C, D or E were excluded.

Informed consent was taken from all participants and permission from ethics committee was sought (copy submitted). Intrapartum management was the same for both the HBsAg carrier and noncarrier cases.

Women were interviewed in Urdu. On the day after delivery, the data was recorded on a predesigned questionnaire that recorded BMI, gestational age at delivery, perinatal outcome (live birth, still birth, intrauterine fetal death). The weight of newborn \& then APGAR score at 1 and 5 minutes were recorded.

The exact gestational age of pregnant women was determined according to last menstrual cycle (LMP) that had been confirmed with ultrasound diagnostic procedure. Gestation hypertension was defined as BP of 140/90 or more on two separate occasions after 20 weeks of gestation.

Preeclampsia was defined as gestational hypertension with proteinuria. Eclampsia was defined as tonic-clonic fits with increased blood pressure. Gestational diabetes mellitus (GDM) was defined as diabetes mellitus occurring during pregnancy. Preterm delivery was defined as delivery before 37 completed weeks of gestation. Low birth weight considered if baby weighed $<2,500 \mathrm{~g}$ at term at birth.

Demographic information of the subjects, antenatal complications (GDM, gestational hypertension, preeclampsia and eclampsia), mode of delivery, labor outcome and perinatal information were analysed.

Data was analyzed using statistical software SPSS version 19.0. Frequency and percentage for qualitative variables. This included maternal age at delivery, BMI, parity and education status.

Differences in variables of obstetric complications (gestational diabetes melitus, gestational hypertension, preeclampsia, eclampsia, preterm delivery, elective LSCS, emergency LSCS ) were 
analysed with the pearson Chi-square test. The $p$ value of $\leq 0.05$ was considered significant.

\section{RESULTS}

Total 9526 pregnant women were delivered during study period. 9305 women fulfilled the

Table-I: Maternal characteristics of hepatitis B carrier and non hepatitis $B$.

\begin{tabular}{l|c|c}
\hline Characteristics & $\begin{array}{c}\text { Non hepatitis B } \\
\mathbf{9 1 0 4}(\mathbf{9 7 . 8 3} \%)\end{array}$ & $\begin{array}{c}\text { Hepatitis B } \\
\text { Carrier } \\
\mathbf{2 0 1}(\mathbf{2 . 1 6} \%)\end{array}$ \\
\hline \multicolumn{2}{l}{ Maternal age at delivery } \\
\hline$\leq 24$ & $1245(13.67 \%)$ & $68(33.83 \%)$ \\
$25-34$ & $7123(78.24 \%)$ & $127(63.18 \%)$ \\
$\geq 35$ & $736(8.08 \%)$ & $6(2.98 \%)$ \\
\hline Body Mass Index (BMI) & $21(10.44 \%)$ \\
\hline $11-19.9$ & $129(1.41 \%)$ & $127(63.18 \%)$ \\
$20-24.9$ & $6127(67.30 \%)$ & $42(20.89 \%)$ \\
$25-29.9$ & $2813(30.89 \%)$ & $11(5.47 \%)$ \\
$\geq 30$ & $35(0.38 \%)$ & $34(16.9 \%)$ \\
\hline Parity & $418(4.59 \%)$ & $139(69.15 \%)$ \\
\hline 1 & $7349(80.72 \%)$ & $28(13.93 \%)$ \\
2 & $1337(14.68 \%)$ & $69(34.32 \%)$ \\
3 & & $101(50.24 \%)$ \\
\hline \multicolumn{2}{|l}{ Educational level } & $31(15.42 \%)$ \\
\hline Un educated & $402(4.41 \%)$ & \\
$\leq 9$ & $3578(39.30 \%)$ & \\
$\geq 10$ & $5124(56.28 \%)$ &
\end{tabular}

inclusion criteria and included in study. Two hundred and twenty one ladies were excluded because of non-fulfilling the inclusion criteria.
We observed that most of pregnant ladies falling in age between 25-34 years. A total of 7123 (78.24\%) of non hepatitis B and 127 (63.18\%) hepatitis B carriers pregnant ladies were present in this age group.

In our study, we found that asymptomatic hepatitis B carrier patients had slightly increased BMI and they were uneducated as compared to non hepatitis B ladies. The table-I showed demographic and socioeconomic characteristics of hepatitis B carrier and non carrier.

There was no statistically significant difference in obstetrical complications such as gestational diabetes mellitus, gestational hypertension and preeclampsia among hepatitis B carriers and non carriers.

In both hepatitis B carriers and non carriers, percentage of mode of delivery such as normal vaginal delivery, elective LSCS or emergency LSCS were also almost the same. In our study, we observed that $4.9 \% \mathrm{HBsAg}$ carriers had preterm delivery while only $2.6 \%$ cases of non $\mathrm{HBsAg}$ carriers had preterm delivery but this difference was not found to be statistically significant.

Perinatal outcome such as live birth rate, low birth weight and APGAR score at $1 \mathrm{~min}$ and 5 min were almost similar in hepatitis $B$ carrier and non carriers. The table-II showed maternal and

Table-II: Comparison of Obstetric complications and outcome in carriers and noncarriers of hepatitis B surface antigen.

\begin{tabular}{|c|c|c|c|}
\hline $\begin{array}{l}\text { Medical disorders, obstetric } \\
\text { complications and outcomes }\end{array}$ & $\begin{array}{l}\text { Non-HBs Agcarriers } \\
\quad(n=9104), n(\%)\end{array}$ & $\begin{array}{l}\text { HBsAg carriers } \\
(\mathrm{n}=201), \mathrm{n}(\%)\end{array}$ & $p$-value \\
\hline Gestational diabetes mellitus & $737(8.09 \%)$ & $16(7.9 \%)$ & 0.944 \\
\hline Eclampsia & $3(0 \%)$ & - & 0.797 \\
\hline Gestational hypertension & $118(1.3 \%)$ & $2(1.0 \%)$ & 0.708 \\
\hline Preeclampsia & $146(1.6 \%)$ & $3(1.4 \%)$ & 0.901 \\
\hline Normal vaginal delivery & $6266(68.8 \%)$ & $140(69.6 \%)$ & 0.802 \\
\hline Elective cesarean section & $1233(13.54 \%)$ & $26(12.9 \%)$ & 0.803 \\
\hline Emergency cesarean section & $1605(17.62 \%)$ & $35(17.4 \%)$ & 0.936 \\
\hline Preterm delivery & $248(2.6 \%)$ & $9(4.9 \%)$ & 0.130 \\
\hline Live birth rate & $9072(99.64 \%)$ & $199(99 \%)$ & 0.134 \\
\hline APGAR Score $<7$ at $1 \mathrm{~min}$ & $364(3.99 \%)$ & $7(3.48 \%)$ & 0.711 \\
\hline APRGAR Score $<5$ at $5 \mathrm{~min}$ & $32(0.35 \%)$ & $1(0.49 \%)$ & 0.932 \\
\hline Birth weight $<2500 \mathrm{~g}$ & $710(7.8 \%)$ & $13(6.4 \%)$ & 0.485 \\
\hline
\end{tabular}

Out of the ladies under investigation, 9104 were HBsAg negative and 201 were hepatitis B carrier. fetal outcomes in hepatitis B carrier and non hepatitis B patient. 


\section{DISCUSSION}

Hepatitis B infection is found worldwide. Its prevalence varies in different parts of world, from country to country, from one region to another region and even from one area to another area in a country. Prevalence of hepatitis B in pregnant women worldwide is $1.5-2.5 \%$ whereas in India it varies from $0.2-7.7 \%{ }^{10}$. In our country, there are estimated 7-9 million carriers of hepatitis $B$ virus with a carrier rate of $3-5 \% 11$. In our study, frequency was found to be $2.16 \%$ amongst indoor antenatal patients whereas study done by Sami et al in Jinnah Post Graduate Medical Centre Karachi shows $5.872 \%$ prevalence in pregnant ladies ${ }^{11}$. An indian study by Katke et al found prevalence of HBsAg carrier status amongst indoor antenatal population around $0.5 \% 12$.

Screening for Hepatitis B during antenatal care is routinely done in all tertiary care setup. In our study $87.2 \%$ were booked, $12.8 \%$ were unbooked. Screening of unbooked cases for hepatitis B was done during hospital admission.

We observed in our study that HBsAg carrier had increased BMI and they were uneducated as compared to noncarrier. Whereas KL Bajema found hepatitis B infected ladies were less commonly overweight or obese $(33 \%$ vs $50 \%$, $p<0.001)$ and older in age (77\% vs $64 \% \geq 26$ year, $p<0.001)^{13}$.

Our study does not show higher rate of antenatal complications such as gestational hypertension, preeclampsia, eclampsia and gestational diabetes mellitus in hepatitis B carrier ladies. These findings are consistent with studies done in Pakistan at Jinnah Postgraduate Medical Institute Karachi11. Indian study by Mishra also showed that antenatal complications were not statically different in both hepatitis B carriers and non carriers ${ }^{10}$. Other international studies such as Indian study by Katke11, United states study by Bajema13, Iranian study by Ebrahimi ${ }^{14}$, Chinese study done by Cui et al15, also show similar findings. Meta-analyses done by Keramat shows same observations ${ }^{16}$. But the study done by Lao
TT shows increased incidence of preeclampsia in HBsAg carrier as compared to noncarrier ${ }^{17}$.

In our study, vaginal delivery, elective and emergency cesarean section rate are comparable in both hepatitis B carrier and non carrier. Study done by Rajshree Dayanand Katke also showed comparable LSCS rate in HbsAg carrier with general population ${ }^{12}$. Whereas higher rate of elective cesarean section was observed in studies done in Hongkong by Mak et al ${ }^{18}$, and in China by Guo et $a l^{19}$. Survey by Guo et al in china suggest that growing awareness and maternal anxiety about maternal to child transmission of hepatitis B virus results in increased elective cesarean section on maternal demand because it is said elective cesarean section and as well as child hepatitis immunization reduce hepatitis $B$ infection rate in infants of HBsAg positive mother ${ }^{19}$. However, the mode of delivery to maximally reduce the incidence of vertical transmission remains controversial. Study done by Pan et al shows HBV infection was transmitted to smaller percentage of infants born by elective cesarean section $(1.4 \%)$ than by vaginal delivery $(3.4 \% p<0.032)$ or emergency cesarean section $(4.2 \% \quad p<0.020)$. Emergency cesarean had no effect on vertical transmission compared with vaginal delivery $(4.2 \%$ vs $3.4 \% p=0.593)^{20}$. The National Institute for Health and Clinical Excellence advises against elective cesarean section for prevention of mother to child transmission of hepatitis $B$, as evidence on this issue is insufficient ${ }^{21}$. But universal screening of all pregnant women, at birth prophylaxis with specific anti-HBV immune globulin as well as HBV vaccination for new-borns of infected women are effective in reducing risk of vertical transmission $^{22}$.

Our study does not suggest worse perinatal outcome in term of low APGAR, low birth weight, NICU admission in hepatitis B positive ladies. Slightly increased risk of preterm birth among carrier of hepatitis B was observed in our study but the difference was not statistically significant. The increased risk of preterm birth may be due to HBV mediated inflammation, which may be due to increases inflammatory cytokine 
production 23,24 . Studies of mother with liver diseases and other chronic inflammatory diseases have shown increased risk of preterm deliveries ${ }^{25}$. A study done by Cui et al showed similar incidence of preterm deliveries, perinatal mortality and low birth weight in newborn of HBV carrier and non HBV carriers women ${ }^{15}$. Metaanalysis done by keramat and younesian shows no significant association between inactive hepatitis B carrier and preterm deliveries ${ }^{17}$.

This study has its limitation, it was conducted in tertiary care hospital which is not representative of the country but it gives insight picture of prevalance of HBV infection in our population and its impact on pregnancy and its outcome. Other limitation of our study was its reliance on retrospective data. Differences in social backgrounds might have played a role in the course of these pregnancies.

\section{CONCLUSION}

In conclusion, inactive hepatitis B carrier status does not increase the risk of pregnancy associated complications such as GDM, gestational hypertension, preeclampsia, stillbirth. It does not change mode of delivery (normal vaginal delivery, emergency elective LSCS or elective LSCS) but this may be a risk factor for preterm birth. It also does not affect neonatal outcomes such as low birth weight, APGAR score at 1 and 5 minute. Women who are inactive hepatitis B carrier can be managed as any other low risk pregnancies if they do not have other antenatal complications or associated risk factors such as additional diseases in pregnancy.

\section{CONFLICT OF INTEREST}

This study has no conflict of interest to be declared by any author.

\section{REFERENCES}

1. Alavian SM, Ebrahimi E, Abedini M. Necessity for HBsAg screening in pregnant women in Ian, needed now. Iran Red Crescent Med J 2016; 18(9): e40844.

2. WHO website. Hepatitis B Key facts. Available from http: // https://www.who.int/en/news-room/factsheets/detail/hepatitis-b.

3. Dalia $R$, Seema $H$, Hepatitis B. In pregnancy: Challenges and solutions. J Gynecol Women’s Health 2016; 1(15): 555572.
4. Karimi-Sari H, Tajik M, Bayatpoor ME, Alavian SM. Increasing the Awareness of the General Population: An Important Step in Elimination Programs of Viral Hepatitis. Am J Gastroenterol 2017; 112(2): 393-95.

5. Ma L, Alla NR, Li x, Mynbaev OA, Shi Z. Mother-to-child transmission of HBV: review of current clinical management and prevention strategies. Rev Med Virol 2014; 24(6): 396-06.

6. American College of Obstetricians and Gynecologists. ACOG Practice Bulletin No. 86: Viral hepatitis in pregnancy. Obstet Gynecol 2007; 110(4): 941-56.

7. Borgia G, Carleo MA, Geta GB, Gentile I. Hepatitis B in Pregnancy. World J Gastroenterol 2012; 18(34): 4677-83.

8. Tang CM, Yau TO, Yu J. Management of chronic hepatitis B infection: current treatment guidelines, challenges, and new developments. World J Gastroenterol WJG 2014; 20(20): 6262-78.

9. Bosan A, Qureshi H, Bile KM, Ahmad I, Hafiz R. A review of hepatitis viral infection in Pakistan. J Pak Med Assoc 2010; 60(12): 1045-58.

10. Mishra S, purandare P, Thakur RS, Agrawal S, Alwani M. Study on prevalence of hepatitis B in pregnant women and its effect on maternal and fetal outcome at tertiary care centre. Int J Reprod Contracept Obstet Gynecol 2017; 6(6): 2238-40.

11. Sami S, Korejo R, Bhutta SZ. Prevalence of hepatitis B and C: A Jinnah postgraduate medical centre experience. J Obstet Gynecol Res 2009; 35(3): 533-38.

12. Katke RD. The impact of maternal HbsAg carrier status on pregnancy outcomes: an institutional experience; Katke, Gynecol Obstet. (sunnyvale) 2015; 5(5): 1-4.

13. Bajema KL, Stankiewicz Karita H, Tenford MW, Hawes SE, Heffron R. Maternal hepatitis B infection and pregnancy outcomes in the united states: A population - based cohort study. Open forum. Infect Dis 2018; 5(6): 134-39.

14. Ebrahimi E, Keramat A, Yunesian M, Alavian SM, Khosravi A, Montazeri A, et al. Maternal inactive hepatitis B status and birth outcomes: A systematic review and meta-analysis. Iran Red Crescent Med J (IRCMJ) 2016; 18(11): e 31820.

15. Cui AM, Cheng XY, Shao JG, Li HB, Wang XL, Shen Y, et al. Maternal Hepatitis B virus status and pregnancy outcomes: a prospective cohort study. BMC Pregnancy Child Birth 2016; 16(1): 87-90.

16. Keramat A, Younesian M, Gholami Fesharaki M, Hosani M, Mirzae S, Ebrahimi E, et al. Inactive Hepatitis B Carrier and pregnancy outcomes: A Systematic Review and Meta-analysis. Iran J Public Health 2017; 46(4): 468-74.

17. Lao TT, Sahota DS, Chang YK, Law LW, Leung TY. Maternal Hepatitis B surface antigen status and incidence of preeclampsia. J Viral Hepat 2013; 20(5): 343-49.

18. MAK SL, Leung KY. Hepatitis B carriers in HKJGOM, prevalence and pregnancy outcomes. Hong Kong J Gynaecol Obstet Mid 2013; 13(1): 67-73.

19. Guo Y, Liu J, Meng L, Meina H, Du Y. Survey of HBsAg-positive pregnant women and their infants regarding measures to prevent maternal-infantile transmission. BMC Infect Dis 2010; 10(1): 26-30.

20. Pan CQ, Zou HB, Chen $Y$, Zhang X, Zhang H, Li J. Cesarean section reduces perinatal transmission of hepatitis $B$ virus infection from hepatitis B surface antigen positive women to their infants. Clinical Gastroenterol Hepatol 2013; 11(10): 1349-55.

21. Gholitabar M, Ulman R, James D, Griffith M. Guidelines: Caesarean section: summary of updated NICE guidance. BMJ 2011; 343(1): 11-14.

22. Gentile I, Borgia G. Vertical transmission of Hepatitis virus: Challenges and Solutions. Int J Women 's Health 2014; 6(1): 605-11. 
23. Lee SM, Park JS, Norwitz ER, Oh S, Kim EJ, Kim SM et al. Midtrimester amniotic fluid pro-inflammatory biomarkers predict the risk of spontaneous preterm delivery in twins: a retrospective cohort study. J Perinatol 2015; 35(8): 542-46.

24. Goldenberg RL, Culhane JF, Iams JD, Romero R. Epidemiology and causes of preterm birth. Lancet 2008; 371(9606): 75-84.

25. Stokkeland K, Ludvigsson JF, Hutcrantz R, Ekbom A, Höijer J, Bottai $\mathrm{M}$, et al. Increased risk of preterm birth in women with autoimmune hepatitis-a nationwide cohort study. Liver Int 2016; 36(1): 76-83. 